\title{
Respiratory Failure and Coma in an International Traveler
}

\author{
Chun-Wei Chang ${ }^{1}$, Ja-Liang Lin ${ }^{2}$, Cheng-Hao Weng ${ }^{2}$ and Tzung-Hai Yen ${ }^{2}$
}

Key words: respiratory failure, coma, body packer, heroin

(Intern Med 50: 2691, 2011)

(DOI: 10.2169/internalmedicine.50.6232)

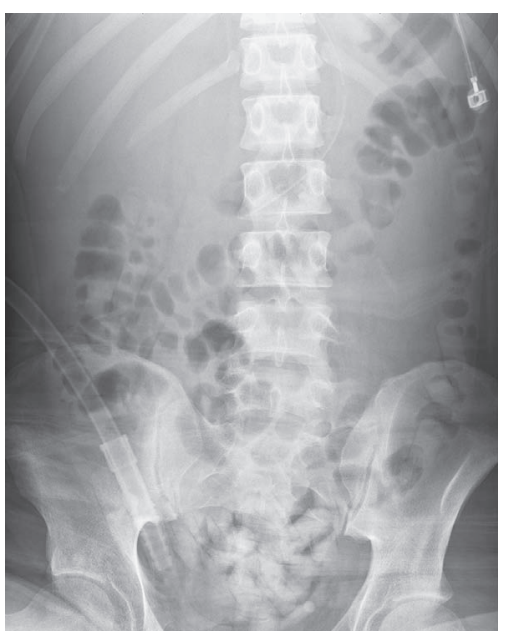

Picture 1.

A 21-year-old foreign man suffered from progressive respiratory distress and consciousness disturbance during his transit at Taoyuan International Airport. Emergent endotracheal intubation was performed, and he was referred to our hospital. On arrival, he was comatose with pinpoint pupils and shock. Blood tests showed leukocytosis and hepatitis. Chest radiography showed pulmonary edema. Urine toxicology testing was positive for morphine, but negative for amphetamine and benzodiazepine. His pupils transiently returned to normal after naloxone injection. Abdominal plain radiography (Picture 1) and computed tomography (Picture 2) found many radiopaque cylinders from the rectum to ascending colon, mostly in the rectum and sigmoid colon. Whole-bowel irrigation revealed that all of the cylinders were actually heroin. The following course was smooth with successful extubation in 4 days. He was discharged in 2
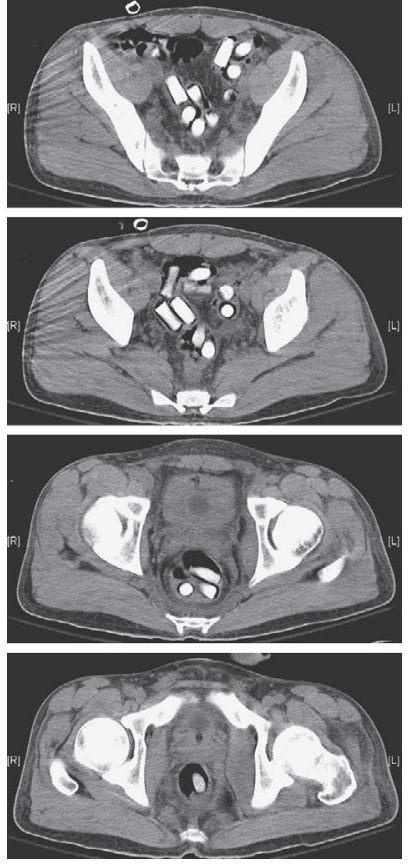

Picture 2.

weeks and transferred to the Foreign Affairs Police Department. Body packing should be suspected in anyone with signs of heroin poisoning after a recent arrival at an airport terminal (1).

The authors state that they have no Conflict of Interest (COI).

\section{Reference}

1. Traub SJ, Hoffman RS, Nelson LS. Body packing--the internal concealment of illicit drugs. N Engl J Med 349: 2519-2526, 2003.

\footnotetext{
${ }^{1}$ Department of Nephrology, Songshan Armed Force General Hospital, Taiwan and ${ }^{2}$ Department of Nephrology and Division of Clinical Toxicology, Chang Gung Memorial Hospital and Chang Gung University, Taiwan

Received for publication July 21, 2011; Accepted for publication July 26, 2011

Correspondence to Dr. Tzung-Hai Yen, m19570@adm.cgmh.org.tw

(C) 2011 The Japanese Society of Internal Medicine Journal Website: http://www.naika.or.jp/imindex.html
} 